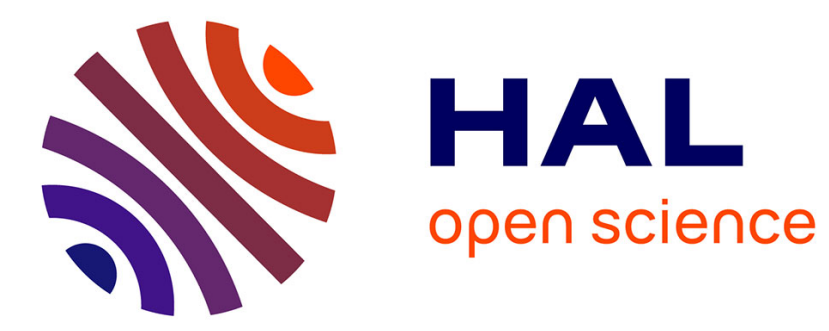

\title{
Local Structural Distortions in Quenched Au-Cu Alloys
}

\author{
A. Frenkel, E. Stern, A. Rubshtein, A. Voronel, Yu. Rosenberg
}

\section{To cite this version:}

A. Frenkel, E. Stern, A. Rubshtein, A. Voronel, Yu. Rosenberg. Local Structural Distortions in Quenched Au-Cu Alloys. Journal de Physique IV Proceedings, 1997, 7 (C2), pp.C2-1005-C2-1006. 10.1051/jp4:19972117 . jpa-00255175

\section{HAL Id: jpa-00255175 https://hal.science/jpa-00255175}

Submitted on 1 Jan 1997

HAL is a multi-disciplinary open access archive for the deposit and dissemination of scientific research documents, whether they are published or not. The documents may come from teaching and research institutions in France or abroad, or from public or private research centers.
L'archive ouverte pluridisciplinaire HAL, est destinée au dépôt et à la diffusion de documents scientifiques de niveau recherche, publiés ou non, émanant des établissements d'enseignement et de recherche français ou étrangers, des laboratoires publics ou privés. 


\title{
Local Structural Distortions in Quenched Au-Cu Alloys
}

\author{
A.I. Frenkel, E.A. Stern, A. Rubshtein*, A. Voronel* and Yu. Rosenberg* \\ Physics Department Box 351560, University of Washington, Seattle, WA 98195-1560, U.S.A. \\ * Sackler School of Physics and Astronomy, Tel-Aviv University, 69978 Tel-Aviv, Israel
}

\begin{abstract}
Disordered alloys $\mathrm{Au}_{x} \mathrm{Cu}_{1-x}$ prepared by melt spinning method were analyzed by XAFS taken at $80 \mathrm{~K}$. Local atomic structure around $\mathrm{Au}$ and $\mathrm{Cu}$ atoms was measured and strong deviations from perfect $f c c$ structure were obtained resulting from the size disparity between $\mathrm{Au}$ and $\mathrm{Cu}$ atoms. A sharp asymmetry was found between the shorter $(\mathrm{Cu}-\mathrm{Cu})$ and the longer ( $\mathrm{Au}-\mathrm{Au})$ nearest neighbor bond lengths. Average first nearest neighbor distance was found greater than obtained using linear interpolation of the pure components. Results on Debye-Waller factors showed strong concentration dependence for the $\mathrm{Cu}-\mathrm{Cu}$ bond, suggesting the loosening of contact between these atoms when the concentration of Au increases.
\end{abstract}

As a result of our extended XAFS study of mixed crystals with atomic size mismatch [1] a basic asymmetry between larger and smaller atoms' behavior has been revealed. The XAFS measurement allows to distinguish an interatomic distance within a particular atomic pair from an interplanar spacing as ascertained by diffraction. Since all the cubic crystals were found to have non-collinear bond structure (buckling [2]), their average interatomic distances, weighted with concentration, had to be always greater than the interplanar spacing. We present results of the XAFS analysis of the quenched $\mathrm{Au}_{x} \mathrm{Cu}_{1-x}$ alloys at $80 \mathrm{~K}$ where the random distribution of $\mathrm{Au}$ and $\mathrm{Cu}$ atoms in the average fcc lattice was accompanied by bond buckling, peaked in the midst of the concentration range. Contact loosening between $\mathrm{Cu}-\mathrm{Cu}$ atoms increased with growing $x$, while $\mathrm{Au}-\mathrm{Au}$ and $\mathrm{Au}$-Cu atoms kept in touch at all concentrations.

Metallic alloys $\mathrm{Au}_{x} \mathrm{Cu}_{1-x}(x=0.06,0.35,0.56,0.80,0.96)$ were prepared by melt spinning method in the Technion, Haifa, Israel. The cooling rate was approximately $10^{5} \mathrm{~K} / \mathrm{sec}$, to ensure the homogeneity of the samples. The homogeneity was verified by X-ray diffraction and no trace of phase separation was observed. The XAFS measurements of $\mathrm{Au} L_{3}$ - and $\mathrm{Cu} K$ - edges were performed on beamline X11A at NSLS at $80 \mathrm{~K}$.

XAFS signals were analyzed by the UWXAFS software [3]. Theoretical scattering amplitudes and phases were generated using the FEFF6 code [4] for the $f c c$ crystal structure model. XAFS analysis was performed concurrently for two edges for each concentration while fitting the FEFF6 theory to data. Changes occurring in the local structure were parameterized in the fit process as corrections to interatomic distances. Mean square deviations of the first nearest neighbor (1NN) bond lengths $\sigma^{2}$ (XAFS Debye-Waller factors) were varied independently for each bond. Parameters of the $\mathrm{Au}-\mathrm{Cu}$ bonds were constrained in the fit to be the same as seen from each edge. Local composition $y$ was allowed to vary in order to account for possible short range ordering of like or unlike atoms.
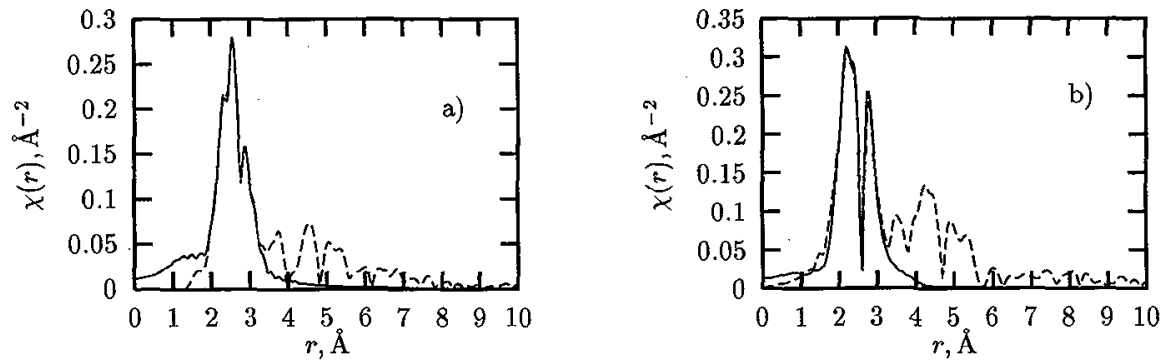

Figure 1: Fourier transforms of the $k$ - weighted XAFS spectra simultaneously fitted with FEFF6 theory (solid) to the data (dash) of $\mathrm{Au}_{0.8} \mathrm{Cu}_{0.2}$ at $80 \mathrm{~K}$ for a) $\mathrm{Au} L_{3}$ and b) $\mathrm{Cu} K$ edges.

Fits to the data are shown in Fig. 1. Local compositions $y$ were found to be equal to the bulk concentrations $x$ of the alloys, indicating absolutely random substitution of atoms. 1NN distances (Fig. 2 a)) show clear asymmetry with respect to the linear interpolation of the pure components, similar to what was obtained previously for the mixed salts $\mathrm{RbBr}_{x} \mathrm{Cl}_{1-x}$ [1]. As discussed in Ref. [1], such asymmetry is a consequence of the local static distortions in the lattice caused bv the asvmmetrv of the redulsive and attraction branches of the interatomic potential. While the 
bond buckling would result in the average $1 \mathrm{NN}$ distance $\left\langle d_{\mathrm{XAFS}}\right.$ 〉 being always greater than the average interplanar spacing $d_{\mathrm{XRD}}$, measured by X-ray diffraction (XRD), our result for the $\left(d_{\mathrm{XAFS}}\right\rangle$ (Fig. 2 a), crosses) almost coincides with the experimental XRD data at the same temperature (the XRD data at $80 \mathrm{~K}$ were obtained by using the room temperature data [5] and correcting by thermal contraction [6] to $80 \mathrm{~K}$ ). This nonlinear dependence of the $d \times \mathrm{XRD}$ with $x$ is consistent with a lattice parameter increase due to the positive tendency to clustering of like atoms in alloys [5], $\mathrm{i}$. e. prepared with insufficiently fast quenching rates and, therefore, non-random. As indicated in Ref. [6], the positive tendency to clustering is just the case for the disordered $\mathrm{Au}-\mathrm{Cu}$ alloys obtained by quenching in water. In our case the randomness of the atomic distribution was assured by the fast quenching rate $\left(10^{5} \mathrm{~K} / \mathrm{sec}\right)$, and, therefore, to illustrate the asymmetry between the repulsion and attraction (as in $\mathrm{RbBr}_{x} \mathrm{Cl}_{1-x}$ [1]) the mean $1 \mathrm{NN}$ distance, (dXAFs), should be compared with the straight line connecting the pure components and corresponding to the $d$ XRD of the absolutely random alloy.
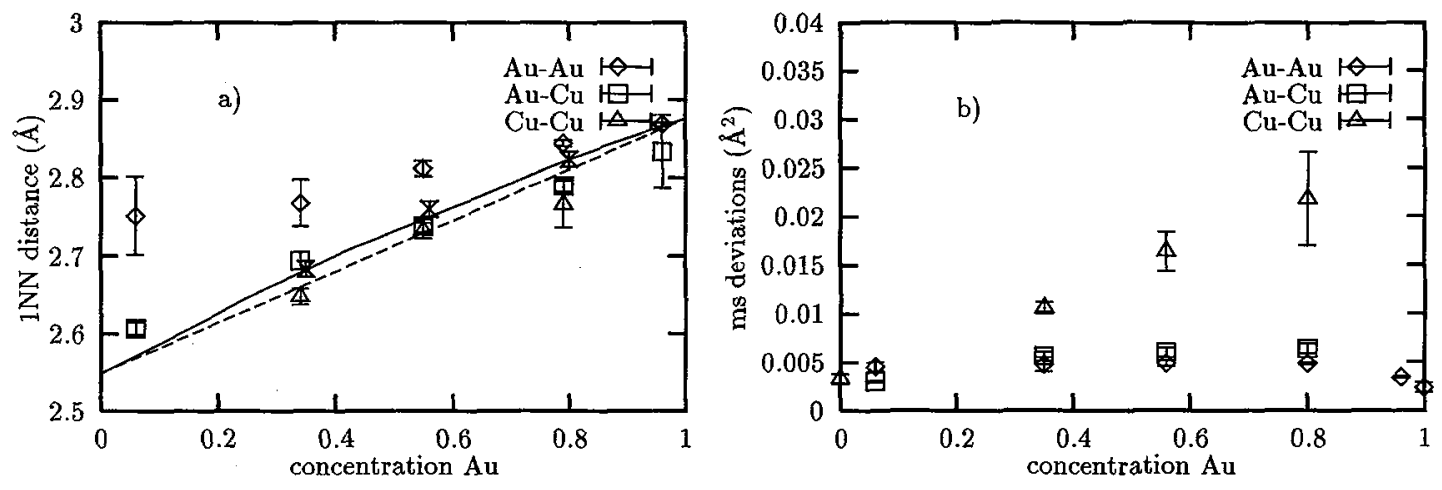

Figure 2: a) $1 \mathrm{NN}$ distances as determined by $\mathrm{x}$-ray diffraction (solid), linearly interpolated with concentration (dash), and measured by XAFS (symbols). Concentration-weighted average 1NN distances obtained with XAFS and shifted for clarity are shown by crosses. b) Mean square deviations of the INN bond lengths.

The different tendency of $\mathrm{Au}-\mathrm{Au}$ and $\mathrm{Cu}-\mathrm{Cu}$ bond lengths to change with concentration was confirmed in the measurements of the Debye-Waller factors (Fig. 2). Consistent with a relatively small decrease in Au-Au bond length with respect to its value in pure $A u$, the $\sigma^{2}$ of this bond does not change strongly with $x$ either. This is in contrast with the $\mathrm{Cu}-\mathrm{Cu}$ bonds which have a drastic increase of $\sigma^{2}$ with $x$, consistent with the Cu-Cu distance expansion to be greater than the $\mathrm{Au}-\mathrm{Au}$ contraction (with respect to the pure metal values). These results indicate that the small $\mathrm{Cu}$ atoms become loosened in the Au matrix at large enough $x(x>0.35)$, and the Cu-Cu 1NN pairs are losing contact, while $\mathrm{Cu}-\mathrm{Au}$ and $\mathrm{Au}-\mathrm{Au} 1 \mathrm{NN}$ pairs remain in contact at all concentrations.

In conclusion, our results show that the rapidly quenched alloys $\mathrm{Au}_{x} \mathrm{Cu}_{1-x}$ are completely random at all $x$. Locally, the structure is buckled about the perfect fcc lattice with the equilibrium positions of $\mathrm{Cu}$ atoms to be most distorted. The buckling is the greatest in the midst of the concentration range, where the difference between the average nearest neighbor distance and the interplanar spacing in the completely random alloy is maximized.

\section{Acknowledgments}

This work was supported by DOE Grant No. DE-FG06-90ER45425. Beamline X11A at NSLS is supported by DOE Grant No. DE-FG05-89ER45384. We thank V. Manov for the help in the sample preparation.

\section{References}

[1] A. Frenkel et al., Sol. St. Comm. 99, 67 (1996), A. Frenkel et al., Physica B 208 \& 209, 334 (1995).

[2] A. Frenkel et al, Phys. Rev. Lett. 71, 3485 (1993).

[3] E. A. Stern et al., Physica B, 208 \&z 209, 117 (1995); The UWXAFS software is licensed through the University of Washington. Further details can be obtained from E. A. Stern.

[4] S. I. Zabinsky et al., Phys. Rev. B 52, 2995 (1995).

[5] G. J. Dienes, Acta Metallurg. 6, 278 (1958).

[6] I. Uszyński, J. Janczak and R. Kubiak, J. of Alloys and Compounds 206, 211 (1994). 